\title{
PERSPECTIVA DA ESTRATÉGIA-COMO-PRÁTICA E O PROCESSO DE FORMAÇÃo DA ESTRATÉGIA ARTICULADA PELA MÉDIA GERÊNCIA
}

\author{
Fernando Eduardo Cardoso \\ fernandoecardoso@ hotmail.com \\ Universidade do Vale do Itajaí - Blumenau, SC / Brasil \\ Rosalia Aldraci Barbosa Lavarda \\ rblavarda@gmail.com \\ Universidade Federal de Santa Catarina - Florianópolis, SC / Brasil
}

http://dx.doi.org/10.1590/1413-2311.0322014.50772

Recebido em 18/07/2014

Aprovado em 21/12/2015

Disponibilizado em 31/12/2015

Avaliado pelo sistema "double blind review"

Revista Eletrônica de Administração

Editor: Luís Felipe Nascimento

ISSN 1413-2311 (versão "on line")

Editada pela Escola de Administração da Universidade Federal do Rio Grande do Sul.

Periodicidade: Quadrimestral

Sistema requerido: Adobe Acrobat Reader

\section{RESUMO}

Este estudo tem como objetivo analisar como ocorre a estratégia-como-prática (implementação da estratégia) quando a organização adota um processo de formação da estratégia deliberada, considerando a ação da média gerência neste processo. Nesta última década o foco dos estudos em estratégia tem sido colocado nas investigações sobre processo, na estratégia-como-prática. Os resultados estratégicos são encontrados nos processos e práticas que constituem o dia a dia das atividades organizacionais. Esses estudos apontam que a estratégia implantada de cima para baixo já não é suficiente e que todos os atores da organização estão envolvidos na implementação das estratégias, caracterizando a estratégia como uma atividade social, considerando que estratégia não é algo que a organização possui, mas sim algo que seus membros realizam. As estratégias podem formar-se nos distintos níveis organizacionais, ou seja, este processo pode ser tanto top-down (deliberado) como bottom-up (emergente), dependendo da necessidade da organização para fazer frente às inconstâncias do ambiente, conduzindo a um processo integrador de formação da estratégia (middle-up-down). Para o alcance do objetivo proposto foi adotada a metodologia qualitativa, por meio do estudo de caso. A partir do fluxo de atividades, das práticas e dos atores organizacionais articulados pela média gerência, se obteve um melhor entendimento da strategizing presente na empresa estudada. A média gerência contribui e influencia na estratégia organizacional, agindo como um facilitador e articulador da estratégia-como-prática. A importância da estratégia-comoprática reside em permitir examinar o que realmente é necessário para que os objetivos organizacionais sejam alcançados com sucesso. A estratégia-como-prática pode ser associada ao conhecimento e ao aprendizado e, assim, ser responsável por uma melhor performance 
PERSPECTIVA DA ESTRATÉGIA-COMO-PRÁTICA E O PROCESSO DE FORMAÇÃO DA ESTRATÉGIA ARTICULADA PELA MÉDIA GERÊNCIA

organizacional, caracterizando o dinamismo do fluxo de atividades, das práticas e dos atores organizacionais articulados pela média gerência.

Palavras-chave: Estratégia-como-prática; Gestor Intermediário; Estratégia Deliberada; Strategizing; Estudo de Caso.

\title{
PERSPECTIVE OF STRATEGY-AS-PRACTICE AND THE PROCESS OF STRATEGY FORMATION ARTICULATED BY THE MIDDLE MANAGER
}

\begin{abstract}
This study aims to analyze how the strategy as practice occurs (strategy implementation) when the organization adopts deliberate strategy formation process, considering the action of middle manager in this process. In the last decade, the focus of studies in strategy has been in the researches of process or in strategy as practice. The results are in strategic processes and practices that constitute the day-to-day of organizational activities. Strategy implemented from top-down is not enough and that all stakeholders of the organization are involved in the implementation of strategies. These studies intend to explain strategy as a social activity, whereas the strategy is not something the organization has but something that its members perform. Thus, strategies can be formed in different organizational levels, i.e., this process can be either top-down (deliberately) as bottom-up (emergent) depending on the needs of the organization to cope with environment dynamism, leading to an integrative strategy formation process (middle-up-down). To achieve the proposed objective a qualitative methodology and a case study was applied. Through the flow of activities, practices and organizational actors articulated by the middle manager, was obtained a better understanding of strategizing, proving that the strategy as practice is present in the studied company. The middle management contribution and influence, organizational strategy, acting as a facilitator and coordinator of the strategy-as-practice. The importance of the strategy-as-practice is to enable examine what is really needed so that organizational goals are successfully achieved. The strategy-as-practice can be associated with knowledge, learning, and thus be responsible for better organizational performance, characterizing the flow of activities, practices and organizational actors articulated by middle management.
\end{abstract}

Keywords: Strategy as practice; Strategizing; Middle manager; Deliberate strategy; Case Study.

\section{PERSPECTIVA DE LA ESTRATEGIA-COMO-PRÁCTICA Y EL PROCESO DE FORMACIÓN DE LA ESTRATEGIA CONDUCIDA POR EL GESTOR DE NIVEL MEDIO}

\section{RESUMEN}

Este estudio tiene como objetivo analizar cómo se produce la estrategia-como-práctica (implementación de la estrategia) cuando una organización adopta un proceso de formación de la estrategia deliberada, teniendo en cuenta la acción del gestor de nivel medio en este proceso. En la última década se ha puesto el foco de estudios en el proceso estratégico y en la

REAd | Porto Alegre - Edição 82 - N 3 - setembro/dezembro 2015 - p. 719-749 
Fernando Eduardo Cardoso \& Rosalia Aldraci Barbosa Lavarda

investigación de la estrategia como práctica. Los resultados estratégicos se encuentran en los procesos y prácticas que constituyen las actividades del día a día de la organización. La estrategia implementada desde arriba hacia abajo ya no es suficiente y todas las partes interesadas de la organización están involucrados en la ejecución de las estrategias. Estos estudios tienen como objetivo explicar la estrategia como una actividad social, mientras que la estrategia no es algo que una organización tiene sino algo que sus miembros realizan. Por lo tanto, las estrategias se pueden formar en diferentes niveles de la organización. Para lograr el objetivo propuesto se adoptó la metodología cualitativa con un estudio de caso. A través del flujo de actividades, prácticas y actores de la organización articuladas por el gestor de nivel medio se obtuvo una mejor comprensión del strategizing en la empresa estudiada. La media gerencia contribuye e influencia en la estrategia organizativa, actuando como facilitador y articulador da estrategia-como-práctica. La importancia de la estrategia-como-práctica es permitir a examinar lo que realmente se necesita para que los objetivos de la organización se logren con éxito. La estrategia-como-práctica puede estar asociada con el conocimiento, el aprendizaje y, por lo tanto, responsable por un mejor resultado en la organización, caracterizando el dinamismo del flujo de actividades, prácticas y actores organizacionales articulados por la media gerencia.

Palabras clave: Estrategia-como-práctica; Gestor Nivel Intermediario; Estrategia Deliberada; Strategizing; Estudio de Caso.

\section{INTRODUÇÃO}

A agilidade, a velocidade, o dinamismo em que se encontra o ambiente organizacional faz com que o processo estratégico requeira a participação de todos os níveis hierárquicos, forçando a evolução da perspectiva top-down, deliberada de tomada de decisão e formação da estratégia para uma perspectiva bottom-up, ou mais emergente, considerada desde a ótica micro-organizacional. Assim, esta evolução proporciona uma nova ênfase, aquela posta no processo ou na perspectiva middle-up-down, ou processo integrador de formação da estratégia (ANDERSEN, 2004).

Por outro lado, os estudos de Floyd e Wooldridge (1992 e 2000), Wooldridge e Floyd (1990), Floyd e Lane (2000), Balogun, Huff e Johnson (2003), Wooldridge, Schmidt e Floyd (2008), Rouleau e Balogun (2011) abordam a questão da participação do nível gerencial ou tático neste processo. A média gerência aparece como ator principal na articulação do processo estratégico organizacional, sendo considerado como o elemento chave para o ajuste estratégico, participando da formulação e implementação da estratégia.

Seguindo esta mesma linha de raciocínio encontra-se a perspectiva da estratégiacomo-prática (JARZABKOWSKI, 2003, 2004, 2005, 2008; JARZABKOWSKI; FENTON, 2006; JARZABKOWSKI; BALOGUN; SEIDL, 2007; JARZABKOWSKI; SPEE, 2009; REAd | Porto Alegre - Edição 82 - N 3 - setembro/dezembro 2015 - p. 719-749 


\section{PERSPECTIVA DA ESTRATÉGIA-COMO-PRÁTICA E O PROCESSO DE FORMAÇÃO DA ESTRATÉGIA ARTICULADA PELA MÉDIA GERÊNCIA}

JARZABKOWSKI; KAPLAN, 2015; JOHNSON; MELIN; WHITTINGTON, 2003; WHITTINGTON, 2006; SEIDL; WHITTINGTON, 2014), em que a organização existe devido às atividades e práticas dos atores que interagem entre si (SCHATZKI, 2005; WHITTINGTON et al., 2006; GOLSORKHI et al., 2010). Esses autores estão focando as questões micro-organizacionais, as estratégias do dia a dia, as atividades realizadas pelos funcionarios e estão dando destaque a atuação do nível da média gerência que executa a tarefa de controlar a equipe e coordenar as pessoas para a realização e implementação das estratégias.

Os pesquisadores da abordagem da estratégia-como-prática estudam as pessoas no contexto organizacional, as atividades rotineiras ou não, atividades realizadas por elas. Segundo Jarzabkowski (2004) faz parte da gama de estudos dos pesquisadores a interação social, o cotidiano dos membros da organização de construção, implementação e controle estratégico.

Este estudo descreve qual o papel da média gerência na implementação das práticas em processo de estratégia deliberada. Estudaram-se as micro práticas desenvolvidas pelas pessoas no seu cotidiano, no dia a dia da organização (seguindo a Strategic Managent Review e os estudos de Whittington, 2006 e 2014 a respeito da necessidade de mais estudos sobre o processo de formação da estratégia e como este ocorre no nível micro-organizacional); assim como a atuação da média gerência e seu envolvimento com o processo de tomada de decisão com uma perspectiva prática das estratégias da organização.

Assim, esta pesquisa tem como objetivo analisar como ocorre a estratégia-comoprática (implementação da estratégia) quando a organização adota um processo de formação da estratégia deliberada, considerando o perfil da média gerência neste processo.

As questões de pesquisa que norteiam este estudo são: Q1) Como é caracterizada a estratégia deliberada na organização? Q2) Como são caracterizadas as atividades práticas que implementam a estratégia deliberada? Q3) Como está caracterizado o perfil da média gerência seguindo a tipologia de Floyd e Wooldridge (1992) na organização?

A tipologia de Floyd e Wooldridge (1992, 1994 e 1997) adotada nesta pesquisa sustenta a ideia de que a média gerência pode ser envolvida e participar ativamente no pensamento e na formação da estratégia. Seus estudos estão divididos em duas dimensões: (i) descrevendo a direção da influência do gerente (para cima ou para baixo), e (ii) avaliando o grau em que esta influência pode alterar a estratégia da organização.

REAd | Porto Alegre - Edição 82 - N 3 - setembro/dezembro 2015 - p. 719-749 
Fernando Eduardo Cardoso \& Rosalia Aldraci Barbosa Lavarda

Floyd e Wooldridge (1992) resumem a tipologia de implicação da média gerência na estratégia, destacando quatro diferentes perfis: (i) defender alternativas; (ii) sintetizar informação; (iii) facilitar a adaptação (iv) implementar a estratégia deliberada. A caracterização do perfil da média gerência será explicada na revisão da literatura.

Este estudo está organizado nos tópicos: (2) Revisão da literatura, onde são abordados temas sobre estratégia-como-prática e o papel da média gerência; (3) Método de pesquisa, onde se apresenta o delineamento metodológico adotado; (4) Análise dos resultados, onde são descritos os resultados encontrados referentes à coleta de dados obtida; (5) Considerações finais, apresentando contribuições, limitações e futuras linhas de pesquisa.

\section{REVISÃO DA LITERATURA}

A estratégia na visão de Chandler (1962, p.13) "é a determinação dos objetivos básicos de longo prazo de uma empresa e a adoção das ações adequadas e de alocação dos recursos necessários para atingir a estes objetivos". Esse conceito é norteador, nesta pesquisa, do entendimento de que a estratégia é um processo composto por deliberações da alta direção e desencadeamento de ações de dentro da organização (estratégia emergente) que sofrem ajustes contínuos para que os objetivos sejam alcançados. Nesse processo de formação da estratégia, se entende que a estratégia é tanto deliberada quanto emergente.

Para Ansoff (1973) a estratégia deliberada ocorre por meio de ações predeterminadas, de forma que se possa planejar e arquitetar as ações antes de colocá-las em prática. Estratégia deliberada para Mintzberg e Waters (1985) ocorre quando as estratégias pretendidas e planejadas são realizadas e segundo Hamel e Prahalad (1994), na estratégia deliberada deve haver um objetivo claro da estratégia, um propósito organizacional, que oriente o futuro criado pela alta direção.

Assim, entende-se que a estratégia deliberada parte da intenção da alta direção, é planejada e estabelece um propósito organizacional (MINTZBERG; WATERS, 1985; HAMEL; PRAHALAD, 1994). 


\section{PERSPECTIVA DA ESTRATÉGIA-COMO-PRÁTICA E O PROCESSO DE FORMAÇÃO DA ESTRATÉGIA ARTICULADA PELA MÉDIA GERÊNCIA}

A estratégia emergente é aquela na qual o padrão realizador não era expressamente pretendido, é uma estratégia que surge de um padrão que não estava previsto, estabelecido (MINTZBERG; WATERS, 1985). Para Hamel e Prahalad (1994), a estratégia emergente é a capacidade de gerar estratégias criativas e as ações correspondentes que surgem e são criadas nos diversos níveis da organização, não se restringindo ao nível de alta direção.

Segundo Mintzberg e Waters (1985) estratégia deliberada e estratégia emergente estão em extremos opostos, em um contínuo de caracterização de diferentes estratégias organizacionais, que combinam vários estágios de dimensões. A principal diferença entre estratégia deliberada e emergente está em considerar o foco, a direção e o controle. $\mathrm{Na}$ estratégia deliberada a ênfase é na direção central e hierarquia, focaliza o controle. Na estratégia emergente a ênfase é na ação coletiva e comportamentos convergentes, focaliza o aprendizado e parece estar relacionada com a estratégia-como-prática (JARZABKOWSKI, 2005; WHITTINGTON, 2006; JARZABKOWSKI; BALOGUN; SEIDL, 2007).

Assim, a soma da estratégia deliberada e emergente dá passagem ao processo integrador de formação da estratégia, o qual equaciona os dois processos anteriores (ANDERSEN, 2004; LAVARDA et al., 2011). Portanto, a formação da estratégia é um processo de formulação, implementação e avaliação. De um lado estão as estratégias deliberadas e do outro as estratégias emergentes.

O processo de formação da estratégia integrador possui a necessidade de um processo estratégico planejado e um processo estratégico descentralizado (ANDERSEN, 2004). O processo planejado está ligado à racionalidade, centralização e formalização em níveis elevados. Por outro lado, o processo estratégico descentralizado está relacionado à participação e envolvimento dos diferentes níveis hierárquicos da organização na tomada de decisão. Assim, a racionalidade e a participação devem se ajustar e se integrar principalmente para atender às necessidades de mudança da organização e do contexto.

É importante destacar que este processo integrador de formação da estratégia requer que o nível médio da hierarquia seja atuante. Esta perspectiva de participação da média gerência no processo de formação da estratégia tem sido desenvolvida por diversos estudos que destacam o papel articulador da média gerência como os principais responsáveis por essa integração estratégica (FLOYD; WOOLDRIDGE, 1992, 1994, 2000; FLOYD; LANE, 2000). 
Fernando Eduardo Cardoso \& Rosalia Aldraci Barbosa Lavarda

\subsection{Estratégia-como-prática}

A estratégia-como-prática é uma perspectiva de estudo da estratégia abordada nas pesquisas de Whittington (1996), Balogun, Huff e Johnson (2003) e, posteriormente, nas pesquisas de Jarzabkowski (2003, 2004, 2005 e 2008) e Jarzabkowski e Kaplan (2015). Entretanto, outros estudos começaram a apresentar abordagens similares, já na década de 80 (SMIRCICH; STUBBART, 1985), quando consideraram a importância do ambiente na construção social e a relação de interação de seus atores, destacando ainda que as pessoas, estrategistas de diferentes níveis e cargos da organização, com suas atuações, que vão determinar como a estratégia será implementada.

Um dos estudos precursores que enfatiza o direcionamento dos estudos em estratégia para uma abordagem de estratégia-como-prática foi o estudo de Whittington em 1996 com a obra "Strategy as practice". Nesse estudo Whittington (1996) analisa as diferentes perspectivas de estratégia (política, planejamento, processo e prática), afirmando que o foco da perspectiva prática é uma estratégia onde os praticantes podem agir e interagir. $\mathrm{O}$ autor ainda completa que a estratégia-como-prática ocorre muito mais pelo conhecimento tácito do que pelo conhecimento formal ou universal.

Balogun, Huff e Johnson (2003) afirmam que devido à globalização, existe a necessidade de se ter uma investigação mais apurada sobre estratégia na prática, a qual deve refletir a larga escala das atividades das empresas e simultaneamente em muitos lugares diferentes.

Hambrick (1981) e Jarzabkowski (2004) afirmam que cada vez mais a estratégia deve ser encarada como uma prática, algo a ser realizado. E conduzem esta perspectiva em duas direções: de um lado a estratégia que existe dentro das organizações, que envolve as pessoas em todos os detalhes necessários (JOHNSON; MELIN; WHITTINGTON, 2003; SAMRA-FREDERICKS, 2003); esta direção de estratégia está muito ligada aos principais gerentes da organização. De outro lado, existem os fatores externos que influenciam a organização da sociedade e que fazem os responsáveis pelos negócios, consultoria e pessoas em geral elaborarem práticas estratégicas que ajudam a adaptar a empresa ao mundo em que se vive (JOHNSON; MELIN; WHITTINGTON, 2003; SAMRA- FREDERICKS, 2003).

Nos estudos de Balogun, Huff e Johnson (2003) o strategizing é o estudo das práticas realizadas pelos seus praticantes no local onde ela ocorre, no contexto em que está inserido. A estratégia-como-prática destaca a forma com que a média gerência realiza suas estratégias,

REAd | Porto Alegre - Edição 82 - N 3 - setembro/dezembro 2015 - p. 719-749 


\section{PERSPECTIVA DA ESTRATÉGIA-COMO-PRÁTICA E O PROCESSO DE FORMAÇÃO DA ESTRATÉGIA ARTICULADA PELA MÉDIA GERÊNCIA}

enfatizando o conceito de strategizing, que relaciona a realização das atividades com a elaboração das estratégias pelos estrategistas. Johnson, Melin e Whittington (2003) complementam que à medida que as atividades geram resultados para organização, mostramse como vantagens competitivas da mesma.

Para Jarzabkowski (2005), a estratégia passa a ser compreendida como um fluxo de atividades organizacionais, em que o pensar e o agir; a formulação e a implementação são suprimidas pela prática estratégica. Jarzabkowski (2005) estuda as dimensões de análise da estratégia-como-prática, classificando três elementos de estudo: praxis, práticas e praticantes.

A praxis está relacionada às ações dos atores, com atividades realizadas pelas pessoas no seu cotidiano organizacional (JARZABKOWSKI, 2005), indicam como são desempenhadas as atividades. Praxis é a adaptação das estratégias existentes de forma a atender as particularidades do dia a dia da organização.

A prática diz respeito a rotinas compartilhadas de comportamento, tradições, normas e procedimentos para pensar e agir. Conjunto de atividades pertencentes ao contexto formal, incluindo normas e expectativas de comportamento, episódios estratégicos e rotinas ostensivas (JOHNSON et al. 2007).

Praticantes são os atores que estão inseridos ou não na organização, que desempenham sua praxis, realizam suas práticas, construindo a estratégia-como-prática (JARZABKOWSKI, 2005). Entre os atores praticantes está a média gerência, que adaptam as práticas, elaborando e colocando em prática as suas próprias praxis.

A intersecção entre estes três elementos: práticas, praxis e praticantes (Figura 1) caracteriza a estratégia sendo realizada ou o strategizing. O strategizing "compreende as ações, interações e as negociações de múltiplos atores e as situações práticas que eles se baseiam na realização das atividades". Refere-se ao "fazer da estratégia", isto é, a construção do fluxo de atividades por meio das ações e interações de múltiplos atores (JARZABKOWSKI; BALOGUN; SEIDL, 2007, p. 11). 
Fernando Eduardo Cardoso \& Rosalia Aldraci Barbosa Lavarda

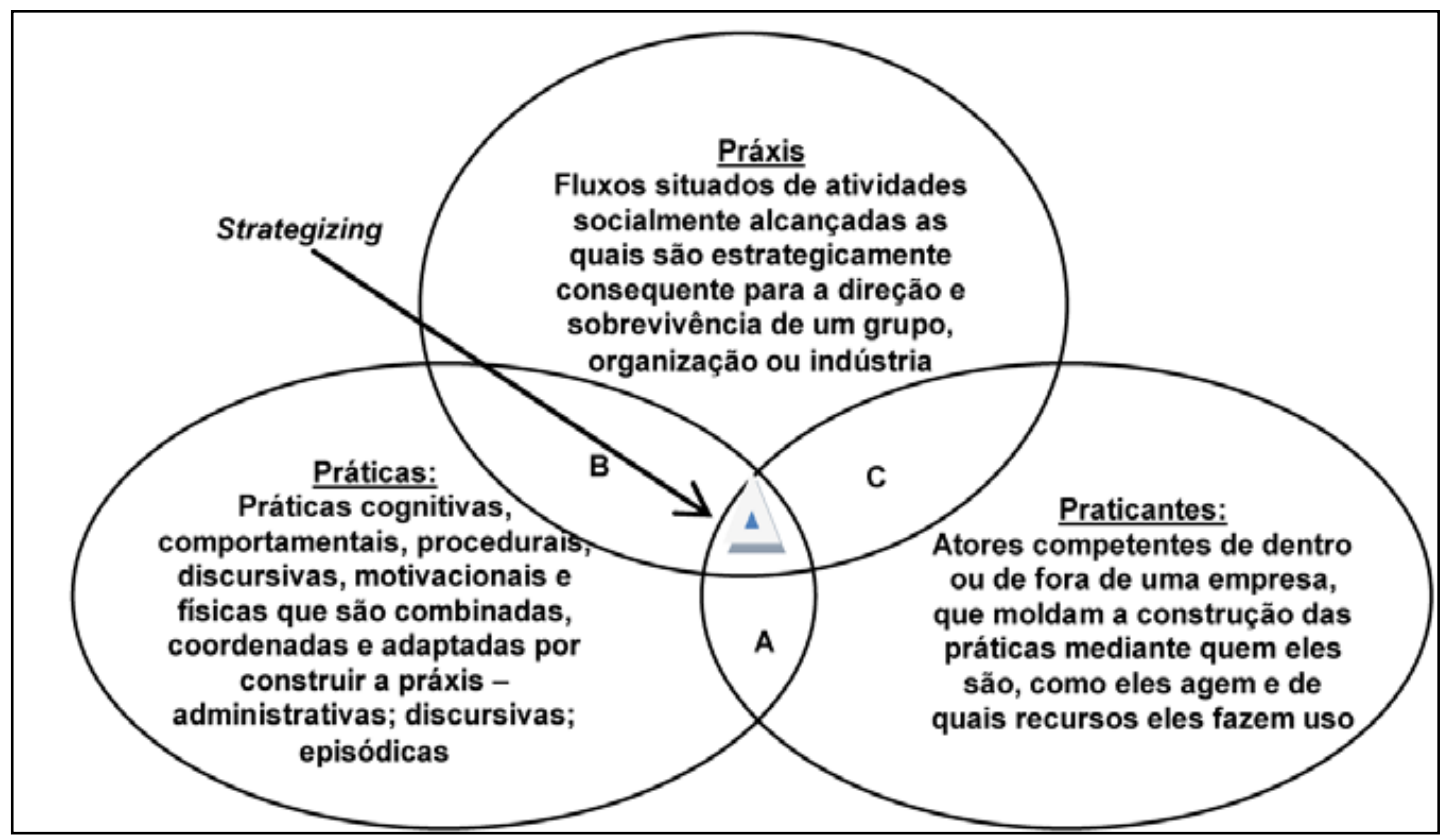

Figura 1 - Estrutura conceptual para analisar a estratégia-como-prática Fonte: Adaptado de Jarzabkowski, Balogun, Seidl (2007, p. 11)

\subsection{O papel da média gerência}

O desempenho organizacional descrito por Burgelman (1983; 1994 e 1996); Nonaka (1988); Floyd e Wooldridge (1992, 1994, 1997 e 2000); Wooldridge e Floyd (1990); Floyd e Lane (2000); Rouleau (2005); Wooldridge, Schmidt e Floyd (2008) e Rouleau e Balogun (2011) é influenciado pela média gerência da organização. Em virtude disto, passa-se a analisar a contribuição, a influência, o papel da média gerência na estratégia organizacional, já que o mesmo pode ser considerado como facilitador e articulador da estratégia-comoprática.

A tipologia de Floyd e Wooldridge (1992, 1994 e 1997) sustenta a ideia de que a média gerência pode ser envolvida e participar ativamente no pensamento e na formação da estratégia. Seus estudos estão divididos em duas dimensões: (i) descrevendo a direção da influência do gerente (para cima ou para baixo), e (ii) avaliando o grau em que esta influência pode alterar a estratégia da organização.

Floyd e Wooldridge (1992) resumem a tipologia de implicação da média gerência na estratégia, destacando quatro tipos de ações: (i) defender alternativas; (ii) sintetizar informação; (iii) facilitar a adaptação e (iv) implementar a estratégia deliberada.

A ação de defender alternativas, conforme Floyd e Wooldridge (1992) é caracterizada por justificar e definir novos programas, avaliar os méritos das novas propostas, 


\section{PERSPECTIVA DA ESTRATÉGIA-COMO-PRÁTICA E O PROCESSO DE FORMAÇÃO DA ESTRATÉGIA ARTICULADA PELA MÉDIA GERÊNCIA}

busca de novas oportunidades, propor programas ou projetos para gerentes de nível superior e justificar programas que já tenham sido estabelecidos. A média gerência com a tipologia de defender alternativas (perfil de defensor) tem a capacidade de mudar o pensamento estratégico dos níveis de diretoria, por meio da introdução de iniciativas estratégicas que divergem da concepção da estratégia em vigor.

Sintetizar informação é um perfil caracterizado por servir informações sobre a viabilidade de novos programas; comunicar as atividades dos concorrentes, fornecedores, etc; Avaliar as mudanças no ambiente externo; e comunicar implicações das novas informações. A média gerência desta tipologia (perfil de sintetizador) interpreta, caracteriza as informações e conduz para cima, para os níveis de diretoria (FLOYD; WOOLDRIDGE, 1992).

Facilitar a adaptação, segundo Floyd e Wooldridge (1992), é incentivar a discussão informal e de partilha de informações; amenizar regulamentos para obter novos projetos iniciados; ganhar tempo com programas experimentais; desenvolver objetivos e estratégias para projetos não oficiais; incentivar a resolução de problemas de equipes multidisciplinares; localizar e disponibilizar recursos para projetos em processo; e proporcionar uma estrutura adequada para programas experimentais. Esta média gerência facilita e adapta as atividades essenciais que estão além das expectativas da diretoria (perfil de facilitador).

Implementar a estratégia deliberada caracteriza-se por monitorar as atividades para dar apoio aos objetivos da diretoria; implementar planos de ação projetados para cumprir objetivos; traduzir objetivos em planos de ação; traduzir objetivos em objetivos individuais. A média gerência que desempenha este papel (perfil de implementador) tem o objetivo de alinhar as atividades organizacionais com a interação estratégica da diretoria (FLOYD; WOOLDRIDGE, 1992).

Para Floyd e Lane (2000), para que a média gerência possa interagir com o nível de diretoria é preciso que entenda qual é o objetivo da organização e sua estratégia competitiva, além do contexto político no qual estão inseridas. Espera-se que a média gerência realize a interação entre o nível operacional e o nível da alta direção. Nesse contexto, o número de interações e a complexidade das informações são maiores para a média gerência do que para os demais níveis de liderança (FLOYD; LANE, 2000).

Pode-se considerar a média gerência como peça fundamental no processo de formação da estratégia, como integrador da visão da diretoria, transmitindo os objetivos e a visão prática da realidade organizacional, proporcionada pelos trabalhadores e podendo até

REAd | Porto Alegre - Edição 82 - N 3 - setembro/dezembro 2015 - p. 719-749 
Fernando Eduardo Cardoso \& Rosalia Aldraci Barbosa Lavarda

intervir e mudar o rumo da organização, com a integração de suas perspectivas de práticas de vida da organização (LAVARDA et al. 2010).

Considerando o marco teórico revisado, e, considerando as questões de pesquisa já apresentadas: Q1) Como é caracterizada a estratégia deliberada na organização? Q2) Como são caracterizadas as atividades práticas que implementam a estratégia deliberada? Q3) Como está caracterizado o perfil da média gerência seguindo a tipologia de Floyd e Wooldridge (1992) na organização? Elaboraram-se três proposições para posterior contrastação empírica, entendendo-se que as proposições procuram responder às questões de pesquisa antes da obtenção dos resultados reais (YIN, 2005, p. 140). Assim, para Q1 temos que, P1: A estratégia deliberada é caracterizada por um processo top-down de tomada de decisão seguindo o modelo de estratégia planejada de Mintzberg e Waters (1985). Para Q2 temos que, P2: As atividades práticas que implementam a estratégia deliberada são pertencentes ao contexto formal e incluem normas e expectativas de comportamento, episódios estratégicos e rotinas ostensivas seguindo o conceito de praxis e práticas de Jarzabkowski, Balogun e Seidl (2007) e, para responder Q3 temos que P3: A média gerência exerce o papel de defensor de alternativas, sintetizador das informações, facilitador da adaptação e implementador da estratégia.

\section{MÉTODO DE PESQUISA}

A presente pesquisa se classifica do ponto de vista da abordagem do problema, como qualitativa, empregando o método de estudo de caso único (EISENHARDT, 1989). Do ponto de vista da forma de abordagem dos objetivos, esta pesquisa caracteriza-se como explicativa, já que tem como objetivo investigar e responder como ocorre a estratégia-como-prática quando as estratégias da organização são deliberadas.

A seleção do caso não foi aleatória, mas intencional (EISENHARDT, 1989), já que o mesmo se constitui, tal como assinala Yin (2005), em um caso propício para estudar as categorias se busca analisar, ou seja, a organização selecionada apresenta condições específicas que favorecem o estudo in loco da estratégia-como-prática e sua relação com a média gerência, por um lado. Por outro, esta seleção se justifica pela participação ativa do pesquisador na organização no período dos últimos doze anos, o que propicia o conhecimento dos grupos sociais de forma ampla, e, em profundidade, assim como o entendimento das suas políticas, cultura, história e ambiente (GODOI et al., 2006). Este estudo foi realizado em uma

REAd | Porto Alegre - Edição 82 - N 3 - setembro/dezembro 2015 - p. 719-749 


\section{PERSPECTIVA DA ESTRATÉGIA-COMO-PRÁTICA E O PROCESSO DE FORMAÇÃO DA ESTRATÉGIA ARTICULADA PELA MÉDIA GERÊNCIA}

indústria têxtil de grande porte, no setor comercial localizada na cidade de Blumenau, no sul do Brasil.

Seguindo o protocolo do estudo de caso, as técnicas de coleta de dados adotadas foram: (i) entrevista semiestruturada, que ocorreu com funcionários dos três níveis organizacionais: alta direção (diretor comercial), média gerência (gerentes, supervisores e coordenadores) e operacional (analistas), Quadro 1.

Quadro 1 - Planejamento das entrevistas

\begin{tabular}{|c|c|c|c|c|}
\hline Data & Duração & $\begin{array}{c}\text { Nível } \\
\text { hierárquico }\end{array}$ & Cargo & Instrumento \\
\hline 09/jul & $1 \mathrm{~h}$ & Alta direção & Diretor Comercial & Entrevista semi-estruturada \\
\hline 24/mai & - & $\begin{array}{c}\text { Média } \\
\text { Gerência1 }\end{array}$ & Gerente de vendas da regional Sul & Entrevista via e-mail \\
\hline 25/mai & - & $\begin{array}{c}\text { Média } \\
\text { Gerência } 2\end{array}$ & $\begin{array}{l}\text { Supervisor de vendas da regional } \\
\text { Centro Oeste }\end{array}$ & Entrevista via e-mail \\
\hline 17/mai & $1 \mathrm{~h}$ & $\begin{array}{c}\text { Média } \\
\text { Gerência } 3\end{array}$ & Coordenador Comercial & Entrevista semi-estruturada \\
\hline 18/mai & $1 \mathrm{~h}$ & $\begin{array}{c}\text { Média } \\
\text { Gerência } 4\end{array}$ & Coordenador Gestão de Distribuição & Entrevista semi-estruturada \\
\hline 19/mai & $1 \mathrm{~h}$ & $\begin{array}{c}\text { Média } \\
\text { Gerência } 5\end{array}$ & Coordenador Informações Gerenciais & Entrevista semi-estruturada \\
\hline 21/mai & $45 \mathrm{~min}$. & Operacional & Analista de informações gerenciais & Entrevista semi-estruturada \\
\hline $21 / \mathrm{mai}$ & 45 min. & Operacional & Analista de gestão de distribuição & Entrevista semi-estruturada \\
\hline 21/mai & 45 min. & Operacional & Analista comercial & Entrevista semi-estruturada \\
\hline
\end{tabular}

(ii) análise dos documentos, que se dividiram em dois grupos: os documentos preparados pela empresa, ex.: planejamento estratégico, organogramas, descrições de cargos, folhetos informativos, referências para a página da empresa na $\mathrm{Web}$; documentos descritivos da política organizacional, publicações internas, boletins, circulares relacionadas ao tema, vídeos institucionais; e, os documentos de terceiros (que não foram produzidos pela própria empresa), por ex.: comunicados de imprensa, publicações especializadas em revistas acadêmicas e informações em outros meios de web sites (notícias);

(iii) observação participante onde, para Yin (2005), o pesquisador não é apenas um observador passivo, mas sim assume funções dentro do estudo de caso podendo participar dos eventos em estudo; destaca-se que neste estudo um dos pesquisadores pode participar da elaboração das atividades analisadas.

(iv) observação direta que, para Chia e Mckay (2007), se constitui em uma fonte de informações; foi realizada tendo como suporte um bloco de anotações na forma de um diário, 


\section{Fernando Eduardo Cardoso \& Rosalia Aldraci Barbosa Lavarda}

onde foram registrados os principais fatos acorridos durante a pesquisa, e no qual foram evidenciadas as mudanças e evoluções ocorridas no período de estudo.

Quanto à análise das evidências é fundamental especificar as categorias utilizadas no processo coleta dos dados e que, posteriormente, facilitaram à análise e geração dos resultados, assim como a relação dessas com as proposições teóricas que pretendem responder às questões de pesquisa (Quadro 2). As categorias de análise servem para orientar a pesquisa nas fases de coleta e análise dos dados, pois, a partir dessa definição, se torna possível a análise detalhada das proposições de estudo (KERLINGER, 1979).

Quadro 2- Questões e Categorias de Análise

\begin{tabular}{|c|c|}
\hline Questões de pesquisa & Categorias de análise \\
\hline $\begin{array}{l}\text { Q1) Como é caracterizada a estratégia deliberada na } \\
\text { organização? }\end{array}$ & C1 - Estratégia deliberada \\
\hline $\begin{array}{l}\text { Q2) Como são caracterizadas as atividades práticas que } \\
\text { implementam a estratégia deliberada? }\end{array}$ & $\begin{array}{l}\mathrm{C} 2-\text { Strategizing } \\
\mathrm{C} 2 \mathrm{a}-\text { Prática } \\
\mathrm{C} 2 \mathrm{~b}-\text { Praxis }\end{array}$ \\
\hline $\begin{array}{l}\text { Q3) Como está caracterizado o perfil da média gerência na } \\
\text { organização? }\end{array}$ & $\begin{array}{l}\text { C3 - Praticante: Perfil da média gerência } \\
\text { C3.a - Defender alternativas } \\
\text { C3.b - Sintetizar informação } \\
\text { C3.c - Facilitar adaptação } \\
\text { C3.d-Implementar estratégia deliberada }\end{array}$ \\
\hline
\end{tabular}

Fonte: Elaboração própria

Destaca-se que a triangulação dos dados foi assegurada usando as fontes de coleta citadas, evitando o viés potencial de uma única fonte de dados e auxiliando na construção de análises mais completas e precisas por meio da convergência das fontes de evidência (EISENHARDT, 1989; YIN, 2005).

A análise integrada das diferentes fontes de coleta de dados (entrevista, observação participante e direta e análise de documentos), nesta fase do estudo (que é mais amplo) se resume à análise de uma atividade específica que será detalhada a seguir.

Assim, adotaram-se as técnicas de análise de dados: a) pattern matching, b) geração de explicações (PÉREZ-AGUIAR, 1999, p.236) e c) análise de narrativa (GODOI, BANDEIRADE-MELLO E SILVA (2006):

a) pattern matching: "é a tática recomendada para comparar eventos, comportamentos ou circunstâncias que possam resultar das proposições teóricas com os acontecimentos, comportamentos ou circunstâncias comprovadas no caso" (PÉREZAGUIAR, 1999, p. 236). A variação da tática pattern matching é denominada exame de padrão de comportamento (EPC), que consiste na formulação do comportamento REAd | Porto Alegre - Edição 82 - N 3 - setembro/dezembro 2015 - p. 719-749 


\section{PERSPECTIVA DA ESTRATÉGIA-COMO-PRÁTICA E O PROCESSO DE FORMAÇÃO DA ESTRATÉGIA ARTICULADA PELA MÉDIA GERÊNCIA}

previsto como uma afirmação, proposição ou hipótese, que será comprovada, transformada ou rejeitada pela prática, pelo comportamento real;

b) geração de explicações: Tática destinada a esclarecer o fenômeno com base em suas causas e interações com outros acontecimentos e circunstâncias, que são apresentados no contexto de uma forma narrativa, servindo como tática que pode completar a análise de padrões nos pontos com maior dificuldade de compreensão, quando não houver clareza ou coerência do estudo, (PÉREZ-AGUIAR, 1999);

c) análise narrativa: Para Godoi, Bandeira-de-Mello e Silva (2006), a análise narrativa leva ao entendimento do texto em sua totalidade, de sua grandeza partindo de suas peculiaridades.

Essas técnicas consistem em comparar o fenômeno real com um padrão de comportamento. Portanto, analisamos a estratégia como prática social por meio das atividades relacionadas à ferramenta de "estratégia de atuação", detalhando as ações envolvidas, como funciona a cultura, o ambiente, o dia a dia da organização (fenômeno real) comparando com o que propõe o marco teórico (proposições do estudo).

\section{ANÁLISE DOS RESULTADOS DO ESTUDO QUALITATIVO}

A caracterização da organização estudada aponta para uma empresa fundada em 1880, por uma família de emigrantes alemães, que participou do desenvolvimento do Vale do Itajaí e do estado de Santa Catarina. É uma empresa de grande porte, atuando no setor têxtil, com faturamento superior a dois bilhões ao ano. Emprega mais de oito mil funcionários, distribuídos nas filiais no estado de Santa Catarina, São Paulo, Goiás e Rio Grande do Norte. A empresa tem mais de 18 mil clientes em todos os estados do Brasil e América Latina, além de mais de 500 lojas próprias e franquias. A empresa (matriz) está dividida em três níveis hierárquicos, alta direção, formada pelo conselho administrativo, presidência e diretoria; média gerência formada pelos gerentes, coordenadores e supervisores e o nível operacional, formado pelos analistas, assistentes, auxiliares e cargos técnicos.

\subsection{Categoria de análise C1 - Estratégia deliberada}


Fernando Eduardo Cardoso \& Rosalia Aldraci Barbosa Lavarda

A estratégia deliberada (C1), ocorre quando as estratégias pretendidas e planejadas são realizadas com origem em planos formais; intenções precisas formuladas e articuladas por uma liderança central; apoiada por controles formais para garantir uma implementação livre de surpresas, em um ambiente controlável ou previsível (MINTZBERG; WATERS, 1985).

A Empresa apresenta um planejamento estratégico formal, desdobrado em planos operacionais. As decisões estratégicas e definição da estratégia global da empresa ocorrem no nível mais alto da organização (conselho administrativo e diretoria), em reuniões periódicas, apoiadas em informações que vêm do ambiente externo e consistentemente apoiadas em reuniões internas que geram as informações necessárias ao adequado processo de tomada de decisão. As decisões tomadas na alta direção são posteriormente repassadas aos níveis da média gerência, que recebem a tarefa de realizar o que foi decidido no nível superior. Os prazos devem ser cumpridos rigorosamente, salvo em ocasiões especiais, onde o não cumprimento dos prazos deve ser muito bem justificado, visando o atendimento de metas e dos objetivos predeterminados.

Entendemos que na Empresa a estratégia deliberada pode ser encontrada, considerando que o nível de planejamento e formalização é bastante elevado, como se pode observar no depoimento da alta direção 1:

O processo de formação da estratégia ocorre partindo de premissas estabelecidas pela diretoria. É a diretoria que elabora as estratégias definidas em reuniões quinzenais com o conselho administrativo que elabora as diretrizes estratégicas da companhia e repassa para os gerentes que fazem com que a estratégia ocorra supervisionada pela direção.

\subsection{Categoria de análise C2 - Strategizing}

Para analisar a categoria Strategizing é pertinente decompô-la em três categorias: C2a Prática e C2b Praxis, descritas neste item e C3 Praticante, separadamente, pois será mais detalhada, já que se propõe estudar o perfil da média gerência. 


\section{PERSPECTIVA DA ESTRATÉGIA-COMO-PRÁTICA E O PROCESSO DE FORMAÇÃO DA ESTRATÉGIA ARTICULADA PELA MÉDIA GERÊNCIA}

\subsubsection{Categoria C2a - Prática}

Corresponde ao conjunto de atividades pertencentes ao contexto formal e incluem normas e expectativas de comportamento, episódios estratégicos e rotinas ostensivas (JARZABKOWSKI; BALOGUN; SEIDL, 2007).

A estratégia-como-prática é identificada quando a alta direção informa ao nível intermediário da empresa quais estratégias foram deliberadas. Então, se inicia a elaboração da estratégia-como-prática articulada pela média gerência com o intuito de garantir a realização das estratégias deliberadas. Como identifica-se no depoimento da média gerência 1:

\footnotetext{
Tendo-se definida a nova estratégia macro da empresa, cabe aos gerentes a elaboração de um plano para que se possam colocar em prática estas estratégias. Para isto, os gerentes de vendas, juntamente com o gerente comercial e seus subordinados, organizarão algumas estratégias que serviram para ajudar a realizar, a cumprir a estratégias macro da empresa.
}

A estratégia-como-prática ocorre no momento em que a média gerência, da área comercial e sua equipe se organizam, utilizando os seus conhecimentos tácitos para criar um plano de como garantir, realizar as estratégias deliberadas elaboradas pela alta direção. Na Empresa, após muito estudo, planejamento, criação de cenários e simulações, a equipe da média gerência da área comercial, com o auxílio de suas equipes, criou as Estratégias, chamadas na empresa de estratégias funcionais, que são: "estratégia funcional de Carteira Ótima", "Estratégia funcional de Curva de Paretto" e "Estratégia funcional de Atuação".

A Estratégia "Carteira Ótima" é definida tomando-se por base o faturamento do cliente e a margem de contribuição. A linha de corte da "carteira ótima" foi estabelecida em um faturamento de até $\mathrm{R}$ \$ 50 mil reais e uma margem de contribuição de $27 \%$. Tanto a linha de corte do faturamento, quanto à margem de contribuição foram decididas em reuniões subsequentes, com a participação da média gerência de cada regional. Lá, utilizaram o seu conhecimento prático para definir os parâmetros de corte, realizando assim a estratégia na prática (JARZABKOWSKI et al. 2007). Com estes parâmetros definidos foi possível classificar os clientes em quatro categorias ou perfis: a) "barganhista"; b) "agressivo"; c) "passivo"; e d) "elite".

O entendimento da média gerência foi de que o "barganhista" são os clientes que compram poucos produtos e com margem baixa para a empresa. Este não é um cliente desejado. Devem ser tomadas ações para que tenha margem maior ou aumente as compras de produtos. O "agressivo" são os clientes com um faturamento alto para a empresa, com REAd | Porto Alegre - Edição 82 - N 3 - setembro/dezembro 2015 - p. 719-749 
Fernando Eduardo Cardoso \& Rosalia Aldraci Barbosa Lavarda

margem baixa. Como este cliente já apresenta um faturamento alto, são necessárias algumas ações para que a margem de lucro também aumente. O "passivo" são os clientes com uma margem de contribuição muito alta, mas com faturamento baixo. É preciso incentivar este cliente a comprar mais (na próxima fase descreveremos as ações que correspondem a este incentivo à compra), mantendo a mesma margem de contribuição. O cliente "elite", que significa o melhor de um grupo, consequentemente, são os clientes ideais da empresa. Apresentam margem de contribuição e faturamento altos, sendo muito lucrativos.

A Estratégia "Curva de Paretto" visa identificar os principais clientes de uma carteira quanto ao faturamento. Ela orienta a média gerência quanto à produtividade dos clientes principais, isto é, o seu nível de participação no faturamento da empresa. Seguindo a teoria de Paretto $20 \%$ dos clientes (clientes principais) devem contribuir com $80 \%$ do faturamento.

A estratégia "Curva de Paretto" é elaborada por meio da classificação dos clientes em relação a sua participação no faturamento da empresa. A linha de corte da "Curva de Paretto" foi estabelecida em 5\%, 15\% e 80\%.

Assim como na estratégia de "Carteira Ótima" a linha de corte do percentual de faturamento foi decidida em reuniões subsequententes, com a participação da média gerência de cada regional e para a classificação da "Curva de Paretto" foi utilizado o conhecimento prático da média gerência para definir os parâmetros de corte, realizando assim a estratégiacomo-prática (JARZABKOWSKI et al. 2007). Com estes parâmetros definidos foi possível classificar os clientes em três categorias ou perfis: a) "Fundamentais"; b) "Importantes"; e c) "Necessários".

Para elaboração da Estratégia de "Atuação" os gestores da empresa se basearam nos estudos de Porter (1986) sobre a matriz de crescimento/parcela que é baseado no uso do crescimento da indústria e da parcela do mercado relativo.

A estratégia de "atuação" é elaborada por meio da classificação do tamanho da loja dos clientes e o percentual de participação dos produtos na loja. A linha de corte da "Atuação" foi estabelecida em um tamanho de loja de $60 \mathrm{~m} 2$ e um percentual de participação dos produtos na loja de 30\%. Tanto a linha de corte do faturamento, quanto à margem de contribuição foram decididas a partir de diversas reuniões, com a participação da média gerencia de cada regional.

Assim como na "Carteira Ótima" e na "Curva de Paretto" foi utilizado o conhecimento prático da média gerência para definir os parâmetros de corte, seguindo rotinas REAd | Porto Alegre - Edição 82 - N 3 - setembro/dezembro 2015 - p. 719-749 


\section{PERSPECTIVA DA ESTRATÉGIA-COMO-PRÁTICA E O PROCESSO DE FORMAÇÃO DA ESTRATÉGIA ARTICULADA PELA MÉDIA GERÊNCIA}

compartilhadas de comportamento, tradições, normas e procedimentos para pensar e agir, realizando assim a estratégia na prática (JARZABKOWSKI et al. 2007).

Com estes parâmetros definidos foi possível classificar os clientes em quatro categorias ou perfis: a) "crescer oportunamente"; b) "crescer participação"; c) "defender posição"; e d) "blindar".

Estratégias estas que são decorrentes das estratégias deliberadas pela alta direção (Quadro 3).

Quadro 3 - Estratégia Deliberada e Práticas estratégicas

\begin{tabular}{|l|l|}
\hline Estratégia deliberada & Práticas estratégicas \\
\hline Reposicionar a marca como moda acessível (a) & Carteira Ótima \\
\hline Buscar relação de valor mais adequada para os produtos da empresa (b) & \\
\hline Aumentar a oferta pública de ações (c) & \multirow{2}{*}{ Curva de Paretto } \\
\hline Aumentar a oferta de crédito na rede de lojas (d) & \\
\hline Ampliar as vendas no varejo multimarcas (e) & \multirow{2}{*}{ Atuação } \\
\hline Expandir a rede de lojas (f) & \\
\hline Aumentar o número de lojas próprias (g) & \\
\hline
\end{tabular}

Fonte: Dados da pesquisa

As estratégias funcionais, elaboradas pelos gestores intermediários do setor comercial, com suporte do nível operacional, tem o intuito de garantir a realização das estratégias deliberadas.

Conforme documentos da tabela de preços da empresa, a estratégia Carteira Ótima emergiu das seguintes estratégias deliberadas: (a) Reposicionar a marca como moda acessível; e (b) Buscar relação de valor mais adequada para os produtos da empresa. Estas duas estratégias deliberadas são atendidas pela estratégia que analisa a questão da margem de lucro para empresa. Se um produto não gera lucro para empresa ou gera lucro muito baixo, o mesmo não é produzido pela empresa.

As estratégias deliberadas de (c) Aumentar a oferta pública de ações; (d) Aumentar a oferta de crédito na rede de lojas; e (e) Ampliar as vendas no varejo multimarcas são garantidas com a realização da estratégia Curva de Paretto. Conforme documento da política comercial da empresa, a ampliação das vendas deriva do aumento do faturamento nos mesmos clientes, gerando pela oferta de créditos pelo uso do cartão de crédito da empresa nas suas lojas. A capitalização causada pela entrada da empresa na bolsa de valores proporciona ao financeiro da empresa investir em projetos como o do cartão próprio. 
Fernando Eduardo Cardoso \& Rosalia Aldraci Barbosa Lavarda

Conforme documento sobre a expansão de lojas, a estratégia deliberada de (f) Expandir a rede de lojas; e (g) Aumentar o número de lojas próprias, é atendido pela Estratégia de Atuação, que atua analisando a participação por metro quadrado das lojas. As estratégias consistiam na classificação dos clientes de acordo com o perfil de compra. Somente após definido o perfil foi possível verificar as ações a serem tomadas para cada grupo de consumidores.

O Quadro 4 mostra as evidências do que foi considerado como estratégias deliberadas e as respectivas estratégias Emergente decorrentes das primeiras realizadas pela média gerencia.

Quadro 4 - Evidencias da estratégia deliberada e estratégia Emergente

\begin{tabular}{|l|l|}
\hline Estratégia deliberada & Estratégia Emergente \\
\hline $\begin{array}{l}\text { Reposicionar a marca como } \\
\text { moda acessível (a) }\end{array}$ & $\begin{array}{l}\text { Aumentando a oferta de produtos e intensificando os investimentos em } \\
\text { propaganda }\end{array}$ \\
\hline $\begin{array}{l}\text { Buscar relação de valor mais } \\
\text { adequada para os produtos da } \\
\text { empresa (b) }\end{array}$ & $\begin{array}{l}\text { Os produtos, como camisetas masculinas, tiveram seus preços reduzidos em } \\
16,3 \% \text { e as calças femininas, em 21,8\%. No entendimento da empresa, } \\
\text { entretanto, não significava está uma estratégia de baixar preços, e sim uma } \\
\text { alternativa para fomentar o varejo }\end{array}$ \\
\hline $\begin{array}{l}\text { Aumentar a oferta pública de } \\
\text { ações (c) }\end{array}$ & $\begin{array}{l}\text { Consolidação dos investimentos planejados para os próximos anos, em } \\
\text { abertura de lojas próprias, tecnologia de informação e tecnologia industrial. }\end{array}$ \\
\hline $\begin{array}{l}\text { Aumentar a oferta de crédito na } \\
\text { rede de lojas (d) }\end{array}$ & $\begin{array}{l}\text { O mapeamento detalhado de shopping centers, corredores comerciais e } \\
\text { bairros residenciais de 135 cidades concluído em agosto de 2007 indicaram } \\
\text { que havia espaço para duplicar o número de lojas }\end{array}$ \\
\hline $\begin{array}{l}\text { Ampliar as vendas no varejo } \\
\text { multimarcas (e) }\end{array}$ & $\begin{array}{l}\text { Além do item (a), propicia condições para a conquista de novos clientes no } \\
\text { varejo multimarcas }\end{array}$ \\
\hline $\begin{array}{l}\text { Expandir a rede de lojas (f) } \\
\text { Um cartão do tipo private label, com características comparáveis às de } \\
\text { outros cartões no mercado foi o foco da estratégia, a ser complementada por } \\
\text { um cartão co-branded e produtos adicionais, como crédito pessoal e seguro. }\end{array}$ \\
\hline $\begin{array}{l}\text { Aumentar o número de lojas } \\
\text { próprias (g) }\end{array}$ & $\begin{array}{l}\text { Aumentar o número de lojas próprias, dentro da rede Store, normalmente } \\
\text { lojas-modelo de maior tamanho, em torno de 200m2 a 240m2 }\end{array}$ \\
\hline
\end{tabular}
Fonte: Dados da pesquisa

Segundo os estudos de Mintzberg e Waters (1985) pode-se chamar estas três estratégias elaboradas pela média gerência de estratégias emergentes, visto que emergiram das próprias média gerência e suas equipes, o nível operacional, da necessidade surgida para atender a um planejamento da alta direção.

\subsubsection{Categoria $\mathrm{C} 2 \mathrm{~b}-$ Praxis}

A praxis está relacionada às ações dos atores, com atividades realizadas pelas pessoas no seu cotidiano organizacional (JARZABKOWSKI, 2005), indicam como são desempenhadas as atividades. Praxis é a adaptação das estratégias existentes de forma a atender as particularidades do dia a dia da organização. 


\section{PERSPECTIVA DA ESTRATÉGIA-COMO-PRÁTICA E O PROCESSO DE FORMAÇÃO DA ESTRATÉGIA ARTICULADA PELA MÉDIA GERÊNCIA}

A praxis é identificada na elaboração das ações e atividades realizadas para atender as estratégias deliberadas, correspondem a ações em conjunto com a participação dos gerentes do setor comercial e com o trabalho do nível operacional como se identificou no depoimento da média gerência 2:

Este trabalho de coleta de ações e atividades que foram sugeridas por cada gerente, foi um trabalho árduo, demorado, que teve certo custo. No entanto, quando vemos o resultado deste trabalho percebemos que tudo valeu à pena. Sem este trabalho não teríamos as ações nem as atividades, não seria possível a consolidação das estratégias de carteira ótima, curva de Paretto e atuação. Sem as atividades e ações todo o trabalho de elaboração das estratégias seria em vão, não saberíamos o que fazer para por em prática as estratégias.

A elaboração das atividades e ações foram as peças que faltavam para garantir a sobrevivência das estratégias deliberadas elaboradas pela alta direção. Nos trechos "foi um trabalho árduo, demorado, que teve certo custo" e "vimos que tudo valeu a pena" percebe-se que os gerentes estão cientes da importância dessa fase para a consolidação da estratégia. Os resultados alcançados reconhecem o esforço e empenho investido na execução dos planos. E apresenta a consciência da importância do consolidação da estratégia para o bom desempenho da organização.

Quadro 5 - Evidências encontradas das categorias C1 e C2

\begin{tabular}{|c|c|c|}
\hline Categoria & Descrição & Evidências encontradas na Empresa \\
\hline $\mathrm{C} 1$ & $\begin{array}{l}\text { Estrategia } \\
\text { Deliberada }\end{array}$ & $\begin{array}{l}\text { - Planejamento estratégico Formal } \\
\text { - Reuniões periódicas } \\
\text { - Estabelecimento de objetivos } \\
\text { - Tomada de decisão na alta direção } \\
\text { - Controles formais }\end{array}$ \\
\hline $\mathrm{C} 2$ & Strategizing & $\begin{array}{l}\text { C2a: Práticas: Discussão da estratégia deliberada } \\
\text { - Apresentação das estratégias nos eventos } \\
\text { - Apresentação de alternativas para alta direção (elaboração das estratégias } \\
\text { Carteira Ótima, Curva de Paretto e Atuação) } \\
\text { - Elaboração do orçamento de receita e despesa } \\
\text { - Reuniões semestrais para discussão de projetos ocorrendo o compartilhamento } \\
\text { de informações, facilitando o debate de informações } \\
\text { - Elaboração de informações gerênciais para o processo de tomada decisão } \\
\text { - Estabelecimento das estratégias de carteira ótima, Curva de Paretto e Atuação } \\
\text { C2b: Praxis: } \\
\text { - Incentivo com prazo de pagamento } \\
\text { - Convite para o cliente participar do show room } \\
\text { - Produção de mais e melhor material de PDV; } \\
\text { - Incentivo a venda de produtos com alta margem } \\
\text { - Programação de compras de clientes com antecedência }\end{array}$ \\
\hline
\end{tabular}

Fonte: Dados da pesquisa 


\section{Fernando Eduardo Cardoso \& Rosalia Aldraci Barbosa Lavarda}

\subsection{Categoria C3 - Praticante: Perfil da média gerência}

Esta categoria indica as características ou os perfis derivados do comportamento da média gerência, considerando o papel estratégico dos gerentes (Floyd \& Lane, 2000) e a contribuição estratégica da média gerência.

\subsubsection{Categoria C3a-Defensor}

Identifica-se o perfil de defensor de alternativa na elaboração das ações estratégicas pelos gestores intermediários e que foram conceituadas pelos mesmos como a aplicação do conhecimento e das ferramentas de controle da oferta e previsão da demanda de maneira integrada, definindo estratégias para obtenção, manutenção e ampliação do mercado, de acordo com o posicionamento das marcas e observando as regras de convivência entre os canais de vendas para a obtenção das metas estabelecidas. Como foi identificado no depoimento da média gerência 3:

\footnotetext{
A criação e elaboração das estratégias, formadas pela Carteira Ótima, Curva de Paretto e Atuação, é um projeto novo que foi colocado em prática num momento em que a empresa precisava identificar o perfil dos seus clientes de forma a poder atendê-los de acordo com as suas necessidades. Estávamos sendo cobrados pela diretoria para realizar um projeto, uma estratégia com resultados rápidos, as ações estratégicas foram a salvação. A nossa carteira de clientes estava muito grande, não era mais possível atender de forma igual a todos os clientes.
}

Conforme se pode observar, no depoimento da média gerência, que participou da elaboração das estratégias-como-prática, o mesmo demonstra preocupação em justificar, avaliar e mostrar resultado desse novo projeto estratégico. Assim, identifica-se o perfil de defensor, durante o processo de elaboração de informações gerenciais, informações estas que são elaboradas pelo nível operacional, e utilizadas pelos gestores intermediários e alta direção da organização para auxiliar no processo de tomada decisão.

\subsubsection{Categoria C $3 b$ - Sintetizador}

O perfil de sintetizador da informação foi identificado na empresa no processo de elaboração do orçamento de receita e despesa da empresa.

Nas palavras da média gerência 4:

O processo de elaboração do orçamento, tanto de receita como de despesa é um processo longo que leva vários meses do ano. No decorrer desse período é levantada

REAd | Porto Alegre - Edição 82 - N 3 - setembro/dezembro 2015 - p. 719-749 


\title{
PERSPECTIVA DA ESTRATÉGIA-COMO-PRÁTICA E O PROCESSO DE FORMAÇÃO DA ESTRATÉGIA ARTICULADA PELA MÉDIA GERÊNCIA
}

\begin{abstract}
uma série de informações econômicas, financeiras, da concorrência e de mercado, além de se identificar os possíveis projetos que serão necessários para o próximo ano a fim de chegar ao orçamento mais próximo do real. No final do ano, no mês de novembro, são fechadas as informações junto com a diretoria e assim pode-se chegar a um orçamento de receita e despesas que atende as necessidades da empresa e dos acionistas.
\end{abstract}

Neste depoimento, no trecho "chegar ao orçamento mais próximo do real" se verifica a preocupação da média gerência em saber que não tem como acertar com exatidão o que vai acontecer no ano seguinte. Mas, com as informações levantadas é possível se aproximar do resultado estimado, tanto de receita como de despesas, da empresa. No trecho "informações econômicas, financeiras" a média gerência evidencia que avalia os fatores externos, que não dependem da organização, favorecendo à alta direção se preparar para turbulências decorrentes da economia interna e externa do país.

\subsubsection{Categoria C3c - Facilitador}

O perfil de Facilitador da adaptação foi identificado na empresa, durante as reuniões semestrais que ocorrem com a média gerência do setor comercial. Nessas reuniões apresenta-se o resultado do último semestre, são discutidos projetos que estão sendo elaborados e futuros projetos, além de ser aberto um espaço para sugestões, críticas e comentários que a média gerência tenha a fazer que sejam referentes às informações ou mesmo a projetos que terão que ser repassados (ou adaptados) para os níveis inferiores.

A média gerência 5 destaca:

\footnotetext{
Eu vejo as reuniões semestrais como um evento importantíssimo para o sucesso do setor comercial. Nestas reuniões podemos expor nossas ideias, críticas e opiniões sobre qualquer assunto ligado ao setor comercial. Podemos falar sobre as coleções, sobre o orçamento, sobre projetos em andamentos e sugestões de projetos, que serão repassados, entre outros assuntos.
}

Pode-se perceber o entusiasmo da média gerência nessas reuniões, pois ele sabe que é o momento onde a direção está disposta a ouvir a opinião deles, facilitando a adaptação dos projetos a serem implementados, os gestores intermediários precisam aproveitar estas reuniões para expor suas dificuldades. 


\subsubsection{Categoria C3d - Implementador}

O perfil de Implementar estratégia deliberada foi identificado na elaboração das informações gerenciais; os gestores intermediários da organização apresentam o perfil de implementar a estratégia deliberada a medida que é exigido dos mesmos: monitorar as atividades para dar apoio aos objetivos da diretoria; implementar planos de ação projetados para cumprir objetivos; traduzir objetivos em planos de ação; traduzir objetivos em objetivos individuais; e vender à diretoria as ideias para os subordinados, Quadro 6.

Quadro 6 - Atividades da média gerência encontradas da categoria C3

\begin{tabular}{|c|c|c|}
\hline C3 & $\begin{array}{l}\text { Praticante: } \\
\text { Perfil da } \\
\text { média } \\
\text { gerência }\end{array}$ & $\begin{array}{l}\text { C3a: - Apresentação de alternativas para alta direção por meio da elaboração das } \\
\text { estratégias Carteira Ótima, Curva de Paretto e Atuação } \\
\text { - Justificativa para a definição de novos projetos } \\
\text { - Avaliação da viabilidade de novos projetos } \\
\text { - Proposição de programas ou projetos para gerentes de nível superior } \\
\text { C3b: - Elaboração do orçamento de receita e despesa } \\
\text { - Elaboração de informações para viabilidade de novos projetos } \\
\text { - Levantamento de informações econômicas, financeiras } \\
\text { - Informações sobre a concorrência } \\
\text { - Dados sobre o mercado } \\
\text { C3c:- Reuniões semestrais para discussão de projetos } \\
\text { - Incentivo à discussão informal } \\
\text { - Compartilhamento de informações } \\
\text { - Incentivo à resolução de problemas de equipes multidisciplinares } \\
\text { - Disponibilização de recursos para projetos em processo } \\
\text { - Facilitação de debate de informações } \\
\text { C3d: - Monitoramento das atividades para dar apoio aos objetivos da diretoria } \\
\text { - Tradução dos objetivos em planos de ação } \\
\text { - Venda da diretoria das ideias para os subordinados }\end{array}$ \\
\hline
\end{tabular}

As tipologias de Floyd e Wooldridge (1992) identificadas na Empresa estão representadas no modelo de perfis (Figura 2), podendo-se exemplificar cada uma das tipologias exercidas pelos gestores intermediários do setor comercial da empresa. 


\section{PERSPECTIVA DA ESTRATÉGIA-COMO-PRÁTICA E O PROCESSO DE FORMAÇÃO} DA ESTRATÉGIA ARTICULADA PELA MÉDIA GERÊNCIA

Para Cima

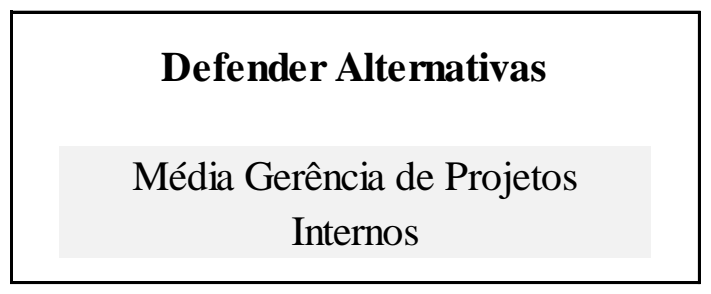

Sinterizador Informação

Média Gerência de Projetos Internos
Para Cima

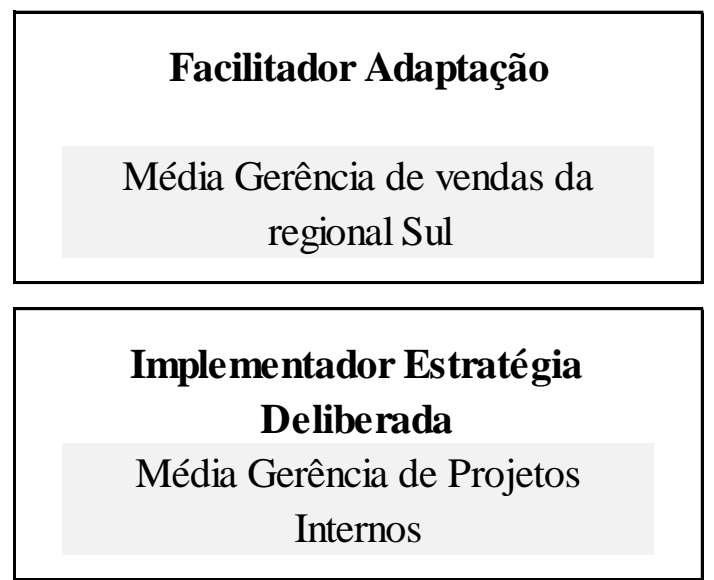

Figura 2 - Perfil da média gerência da Empresa

Fonte: Adaptado de Floyd e Wooldridge, (1992)

\subsection{Análise e discussão das questões e proposições}

Passa-se a analisar cada proposição em relação ao caso estudado, considerando que as questões e proposições de pesquisa foram estabelecidas como decorrência do marco teórico e prévias ao estudo empírico.

Assim, para a questão Q1: Como é caracterizada a estratégia deliberada na organização? Foi estabelecido que: P1 - A estratégia deliberada é caracterizada por um processo top-down de tomada de decisão seguindo o modelo de estratégia planejada de Mintzberg e Waters (1985).

A proposição de que a estratégia deliberada é caracterizada por um processo topdown de tomada de decisão, considerando as evidências encontradas na análise da categoria $\mathrm{C} 1$, foi confirmada na Empresa. Também foi possível identificar a presença do processo de formação da estratégia do tipo guarda-chuva de Mintzberg e Waters (1985), quando se encontrou ênfases de "lideranças com controle parcial das ações, definição de limites estratégicos ou alvos dentro dos quais outros atores respondem às suas experiências" conforme estabelecem os autores.

Para P1 a estratégia deliberada no caso estudado é caracterizada por um processo top-down de tomada de decisão conforme depoimento do diretor comercial.

No trecho "As decisões tomadas nestas reuniões são levadas às gerências que ficam responsáveis por colocar em prática, por executar as decisões estratégias tomadas nas reuniões 


\section{Fernando Eduardo Cardoso \& Rosalia Aldraci Barbosa Lavarda}

operacionais." evidencia o processo top-down de tomada de decisão; os diretores e o conselho administrativo se reúnem quinzenalmente para decidirem qual estratégia deve ser seguida.

No trecho "Previamente a estas reuniões cabe a cada direção conversar com os seus gerentes para que se possam projetar cenários otimistas, realistas e pessimistas", se destaca que a tomada de decisão é feita baseada em cenários que são previamente elaborados em conjunto com a gerência.

Considerando a questão Q2: Como são caracterizadas as atividades práticas que implementam a estratégia deliberada? Foi estabelecido que: P2 - As atividades práticas que implementam a estratégia deliberada são pertencentes ao contexto formal e incluem normas e expectativas de comportamento, episódios estratégicos e rotinas ostensivas seguindo o conceito de práticas e praxis de Johnson et al (2007).

As normas, regras e procedimento foram identificados na reconfiguração do administrativo de vendas, onde cada funcionário teve que descrever as suas atividades, fossem elas rotineiras ou não, e detalharam as rotinas alocando o tempo que leva para realização das mesmas.

A descrição das normas, práticas, e rotinas no processo de reconfiguração evidencia a formalização das práticas da empresa em um documento formal chamada de "definição estratégica do cargo" onde cada funcionário pode analisá-las, estudá-las e propor melhorias nas práticas realizadas e formalizadas na empresa. A reconfiguração ainda proporcionou agilidade das gerências na distribuição de atividades que viessem a auxiliar no processo decisório da organização. Com as normas em mãos a gerência soube identificar qual o analista que poderia ajudar na elaboração de cenários para tomada de decisão.

Considerando as evidências encontradas na análise das práticas e praxis, entende-se que estas confirmam P2, como se pode verificar no depoimento da média gerência 4:

\footnotetext{
Fomos pioneiros no que chamamos de reconfiguração do administrativo de vendas, onde definimos a estratégia de cada cargo. Para tanto, foram levantadas as atividades de cada funcionário. Descrevemos os procedimentos, a rotina que cada funcionário tem que realizar diariamente, o tempo que leva para se fazer cada atividade, e quais as ferramentas usadas para realização das mesmas. Com a realização da reconfiguração conseguimos identificar quais pessoas estavam com muitas atividades, e quais estavam ociosas. Nos casos onde o funcionário estava ocioso foram atribuídas novas atividades de forma que ocupasse todo o seu tempo de trabalho. Aos que estavam com muitas atividades e, por isto mesmo ficavam vários dias trabalhando após o horário normal de trabalho, para estas pessoas, foram contratados novos funcionários, de forma a poder distribuir as atividades que até então eram realizadas por apenas um funcionário.
} 


\section{PERSPECTIVA DA ESTRATÉGIA-COMO-PRÁTICA E O PROCESSO DE FORMAÇÃO DA ESTRATÉGIA ARTICULADA PELA MÉDIA GERÊNCIA}

Considerando a questão Q3: Como está caracterizado o perfil da média gerência na organização? Foi estabelecido que:

P3 - A média gerência exerce o papel de defensor de alternativas, sintetizador das informações, facilitador da adaptação e implementador da estratégia (FLOYD; WOOLDRIDGE, 1992).

A tipologia de Floyd e Wooldridge (1992) foi identificada por meio da análise das categorias C3a, C3b, C3c e C3d evidenciando que a empresa apresenta em sua média gerência todos os perfis da tipologia. Entende-se que foi possível identificar nas diversas atividades analisadas características de cada perfil. Neste estudo de caso, os perfis foram analisados em conjunto, observando as características das funções dos cargos e não das pessoas. Não se analisou a intensidade de cada perfil ou sua representatividade em relação ao outro.

A P3 se confirma, pois o trabalho em equipe da média gerência com perfis diferentes conduzem ao alcance dos resultados previamente planejados, conforme depoimento da média gerência 3:

\footnotetext{
Eu percebo, nestes vários anos de empresa, mas me chamou a atenção agora na área de projetos internos que o trabalho em equipe dos gerentes proporciona uma estratégia mais correta. Os gerentes quando trabalham em equipe, pelo conhecimento, e pelo perfil que cada um apresenta, de que as estratégias, as decisões tomadas em conjunto por eles sempre, ou geralmente dão certo. A inteligência deles em planejar as três estratégias baseadas na estratégia macro da empresa é uma prova de que a união de personalidades diferentes só tem a contribuir com o sucesso da empresa.
}

Fica evidenciado que a média gerência exerce o papel de defensor de alternativas, sintetizador das informações, facilitador da adaptação e implementador da estratégia, de acordo com o modelo proposto por Floyd e Wooldridge (1992), confirmando-se todas as proposições estabelecidas neste estudo.

\section{CONSIDERAÇÕES FINAIS}

O objetivo desta pesquisa foi analisar como ocorre a estratégia-como-prática (implementação da estratégia) quando a organização adota um processo de formação da estratégia deliberada, considerando a ação da média gerência neste processo. 
Fernando Eduardo Cardoso \& Rosalia Aldraci Barbosa Lavarda

Para atingir este objetivo desenvolveu-se um estudo de caso, no qual se procurou evidenciar o dia a dia da estratégia, em um período de 40 meses, acompanhando o desenvolvimento de diferentes fases da estratégia da organização. Encontrou-se que a diretoria exerce o papel de repassar as estratégias macro da organização (estratégia deliberada) cabendo aos atores da organização (conceito de praticantes de JARZABKOWSKI; BALOGUN; SEIDL, 2007) a elaboração das atividades para implementar a estratégia vinda da alta direção, visto que eles, os atores, são especialistas na área em que atuam proporcionando melhores práticas, atuando de forma eficiente no alcance dos objetivos traçados nas macro estratégias.

O recorte feito neste estudo permitiu estudar com maior profundidade determinadas ações estratégicas que foram consideradas como a estratégia sendo posta em prática; foi possível conhecer a dimensão da cultura da organização estudada, bem como a construção, no dia a dia, da estratégia-como-prática (JARZABKOWSKI; BALOGUN; SEIDL, 2007).

Pode-se observar que, apesar de a organização possuir estratégias deliberadas, a estratégia-como-prática não é engessada, sofre forte influência da média gerência organizacional. A média gerência é a intermediadora das estratégias deliberadas, sendo responsável pela elaboração da estratégia no dia a dia da empresa.

A importância da estratégia-como-prática, reside em permitir examinar o que realmente é necessário para que os objetivos organizacionais sejam alcançados com sucesso. A estratégia-como-prática pode ser associada ao conhecimento, ao aprendizado, e assim, ser responsável por uma melhor perfomance organizacional. Por meio do fluxo de atividades, das práticas e dos atores organizacionais articulados pela média gerência, como previsto nos estudos de Golsorkhi et al., 2010.

A média gerência utiliza seu conhecimento prático na tomada de decisões, influenciando nas estratégias deliberadas e até mesmo definindo novas estratégias; as estratégias que emergiram do meio, do dia a dia, exercendo o papel de articuladora da estratégia.

Assim, entende-se que foram alcançados os três objetivos específicos propostos nesta pesquisa, ou seja, foi possível (i) caracterizar estratégia deliberada; (ii) identificar as atividades práticas que caracterizam a implementação da estratégia; e de (iii) analisar o perfil da média gerência.

Os resultados analisados indicam que uma organização com processo deliberado, como foi este caso, também apresenta no seu processo de implementação atividades que são REAd | Porto Alegre - Edição 82 - N 3 - setembro/dezembro 2015 - p. 719-749 


\section{PERSPECTIVA DA ESTRATÉGIA-COMO-PRÁTICA E O PROCESSO DE FORMAÇÃO DA ESTRATÉGIA ARTICULADA PELA MÉDIA GERÊNCIA}

revistas ou modificadas em função das condições do meio (interno ou externo) necessitando de readaptação (estratégias emergentes), caracterizando a estratégia-como-prática que é fortemente articulada pelo nível de gerência. Ou seja, embora a estratégia seja deliberada ou planejada, no conceito de Mintzberg e Waters (1985), ao ser implementada por meio de atividades e práticas, no conceito de práticas e praxis de Jarzabkowski, Balogun e Seidl (2007), sofre forte influência dos atores organizacionais, representados ou articulados pela média gerência, seguindo a tipologia de Floyd e Wooldridge (1992). Entende-se, portanto, que a perspectiva da estratégia-como-prática e o processo de formação da estratégia são articulados pela média gerência.

As contribuições ou implicações deste estudo podem ser apontadas ao ambiente empresarial e ao ambiente acadêmico. No ambiente empresarial, considera-se que os resultados deste estudo podem contribuir para que organização possa fortalecer as relações que envolvem o nível gerencial no processo de formação da estratégia, já que esta empresa foi considerada pela Revista Exame Melhores e Maiores 2010 como uma das Melhores Empresas do ano de 2010.

No ambiente acadêmico, destaca-se que o estudo deste caso propiciou conhecer o processo de formação da estratégia em uma organização específica, classificada como uma das maiores do setor têxtil do Estado de Santa Catarina, em profundidade. O estudo qualitativo tem ganhado força nos estudos sobre processo. Acredita-se que este tipo de estudo contribui para o avanço do campo cientifico e como primeiro passo para estudos quantitativos que possam generalizar os resultados aqui encontrados.

A principal contribuição deste estudo está em combinar o estudo da estratégia-comoprática e o papel da média gerência em uma organização que adota estratégia deliberada.

Quanto à limitação desta pesquisa, destaca-se a questão do "olhar do pesquisador", que pode apresentar vieses na pesquisa. Apesar dos cuidados metodológicos seguidos para assegurar a réplica científica, e a revisão de literatura que fundamentou teórica e empiricamente o assunto, se considera o mesmo como o início de um caminho que conduz a pesquisas complementares.

Porém, os dados obtidos no presente estudo, com as devidas precauções, considerando-se as diferenças organizacionais, culturais, regionais e temporais, podem ser utilizados em estudos de mesma natureza e similaridade.

REAd | Porto Alegre - Edição 82 - N $^{\circ} 3$ - setembro/dezembro 2015 - p. 719-749 
Fernando Eduardo Cardoso \& Rosalia Aldraci Barbosa Lavarda

Como futuras pesquisas indica-se a continuidade desta investigação, aprofundando os conhecimentos aqui apresentados, no mesmo contexto de pesquisa, e em outros semelhantes, que possibilitem realizar em um momento subsequente estudos comparativos. Da mesma forma, se julga importante a realização de estudos que considerem a estratégiacomo-prática em outros ambientes organizacionais para ampliar o conhecimento sobre o tema.

Por outro lado, considerando a estratégia um processo, fica a perspectiva de uma análise à luz da abordagem processual.

\section{REFERÊNCIAS}

ANDERSEN, T. J. Integrating the Strategy Formation Process: Na International Perspective, European Management Journal, 22, 3, 263-272, 2004.

ANSOFF, I. Business strategy. Great Britain: Perguin Books, 1973.

BALOGUN, Julia; HUFF, Anne S.; JOHNSON, Phyl. Tree Responses to the Methodological Challenges of Studying Strategizing. Journal of Management Studies, 40, 1, 2003.

BURGELMAN, R. A. A model of the interaction of strategic behaviour, corporate context, and the concept of strategy. Academy of Management Review, 8, 1:61-70, 1983a.

Fading Memories: a Process Theory of Strategic Business Exit in Dynamic Environments, Administrative Science Quarterly, 39, 1, 24-56, 1994.

A process Model of Strategy Business Exit: Implications of an Evolutionary

Perspective on Strategy, Strategic Management Journal, Summer Special Issue, 1, 17, 193 214, 1996.

CHANDLER, Alfred D. Strategy and structure: chapters in the history of the industrial enterprise. Cambridge, MA: MIT Press, 1962.

CHIA, R.; MCKAY, B. Post Processual Challenges for the Emerging Strategy-as-Practice Perspective. Human Relations, 60, 1, 2007. 
PERSPECTIVA DA ESTRATÉGIA-COMO-PRÁTICA E O PROCESSO DE FORMAÇÃO DA ESTRATÉGIA ARTICULADA PELA MÉDIA GERÊNCIA

EISENHARDT, K. Building theories from case study research. Academy of Management Review, 14, 4, 532-550, 1989.

EXAME, Melhores e maiores. As 1000 maiores empresas do Brasil, Edição especial julho, 48-58, 2010.

FENTON, A.; LANGLEY, C. Strategy as Practice and the Narrative Turn. Organization Studies, v. 32, p. 1171-1198, 2011.

FLOYD, S. W.; LANE, P. J. Strategizing Throughout the Organization: Managing Role Conflict in Strategic Renewal, Academy of Management Review, 25, 1, 154-77, 2000.

.; WOOLDRIDGE, B. Middle management involvement in strategy and its association with strategic type: A research note. Strategic Management Journal, 13: 153-67, 1992.

; __ Dinosaurs or Dynamos? Recognizing Middle Management's Strategic Role. Academy of Management Executive, 8, 4, 47-57, 1994.

; __. Middle Management's Strategic Influence and Organizational Performance,

Journal of Management Studies, 34, 3, 465-85, 1997.

; __ B. Building Strategy from the Middle: Reconceptualizing Strategy

Process, Thousand Oaks, CA: Sage, 2000.

GODOI, Christiane Kleinubing; BANDEIRA-DE-MELLO, Rodrigo; SILVA, Anielson Barbosa da. Pesquisa qualitativa em estudos organizacionais: paradigmas, estratégias e métodos. São Paulo: Saraiva, 2006.

GOLSORKHI, Damon; ROULEAU, Linda; SEIDL, David; VAARA, Eero. Cambridge Handbook of Strategy as Practice. Cambridge: Cambridge University Press, 2010.

HAMBRICK, D. C. Environment, strategy and power within top management teams. Administrative Science Quarterly, 26: 253-76, 1981.

HAMEL, G.; PRAHALAD, C. K. Competing for the future. Harvard Business Review, Jul.Ago, 122-128, 1994. 
Fernando Eduardo Cardoso \& Rosalia Aldraci Barbosa Lavarda

JARZABKOWSKI, P. Strategic Practices: an Activity Theory Perspective on Continuity and Change, Journal of Management Studies, 40, 1, 23-55. 2003.

Strategy as practice: Recursiveness, adaptation and practices-in-use. Organization Studies. 24, 3: 489-520. 2004.

.Strategy as practice: an activity-based approach. California: Sage, 2005.

Shaping Strategy as a Structuration Process. Academy of Management Journal, 51, 4: 621-50, 2008.

.; FENTON, E. Strategizing and Organizing in Pluralistic Contexts. Long Range Planning, 39, 631-48, 2006.

BALOGUN, Julia; SEIDL, David. Strategizing: The Challenge of a practice perspective.Human Relation, 60, 5-67, 2007.

.; SPEE, Andreas Paul. Strategy-as-practice: A review and future directions for the Field. International Journal of Management Reviews, 1, 1, 69-95, 2009.

.; KAPLAN, S. Strategy tools-in-use: A framework for understanding "technologies of rationality" in practice. Strategic Management Journal. 36, 537-558, 2015.

JOHNSON, G.; MELIN, L.; WHITTINGTON. R., Micro-strategy and strategizing towards an activity-based view. Journal of Management Studies, 40, 1, 3-22, 2003.

; LANGLEY, A.; MELIN, L.; WHITTINGTON, R. Strategy as practice: research directions and resources. London: Cambridge, 2007.

KERLINGER, F. N. Metodologia da pesquisa em ciências sociais: um tratamento conceitual. São Paulo: EPU/EDUSP, 1979.

LAVARDA, R.; CANET-GINER, M. T.; PERIS-BONET, F. How middle managers contribute to strategy formation process: connection of strategy processes and strategy practices. Revista de administração de Empresas (RAE), São Paulo, 50 (4), out./dez. 358$370,2010$.

;____ _ _ Understanding how the strategy formation process interacts with the management of complex work. European Business Review, v. 23, p. 71-86, 2011. 
PERSPECTIVA DA ESTRATÉGIA-COMO-PRÁTICA E O PROCESSO DE FORMAÇÃO DA ESTRATÉGIA ARTICULADA PELA MÉDIA GERÊNCIA

MINTZBERG, H.; WATERS, J. Of strategies, deliberate and emergent. Strategic Management Journal, 6, 3, 257-272, 1985.

NONAKA, I. Toward Middle-up-down Management: Accelerating Information Creation, Sloan Management Review, 29, 3, 9-18. 1988.

PÉREZ-AGUIAR, W. El estudio de Casos. En Sarabia, F. J. (Ed.): Metodología para la investigación en marketing y dirección de empresas, Madrid: Pirámide. 1999.

ROULEAU, L. Micro-Practices of Strategic Sensemaking and Sensegiving: How Middle Managers Interpret and Sell Change Every Day, Journal of Management Studies, 42, 7, 14,13-41. 2005.

ROULEAU, L., BALOGUN, J. Middle managers, strategic sensemaking, and discursive competence. Journal of Management Studies, 48, 5, 953-983, 2011.

SAMRA-FREDERICKS, D. Strategizing as lived experience and strategists' everyday efforts to shape strategic direction. Journal of Management Studies 40, 1, 141-174 -2003.

SEIDL, D., WHITTINGTON, R. Enlarging the strategy-as-practice research agenda: Towards taller and flatter ontologies. Organization Studies, 7, 1-15, 2014.

SCHATZKI, T. R. The sites of organizations. Organization Studies. 26, 3, 465-484, 2005.

WHITTINGTON, R. Strategy as practice. Long Range Planning, 29, 5, 731-735, 1996. 634, 2006.

Completing the practice turn in strategy research. Organization Studies, 27, 5, 613-

Making strategy: the hard work of institutional innovation in an open professional field. In: Annals of XIV EURAM - European Academy of Management Annual Meeting, Valencia, 2014.

MOLLOY, E. MAYER, M. e SMITH A. Practices of Strategising/Organising. Long Range Planning, 39:615-629, 2006.

WOOLDRIDGE, B., SCHMIDT, T., \& FLOYD, S. W. The middle management perspective on strategy process: contributions, synthesis, and future research. Journal of management, 34, 6, 1190-1221, 2008.

REAd | Porto Alegre - Edição 82 - N 3 - setembro/dezembro 2015 - p. 719-749 
Fernando Eduardo Cardoso \& Rosalia Aldraci Barbosa Lavarda

YIN, R. K. Estudo de caso: planejamento e métodos. 3. ed. Porto Alegre, RS: Bookman, 2005. 212 p. il. Tradução de: Case study research: design and methods, 1994. 